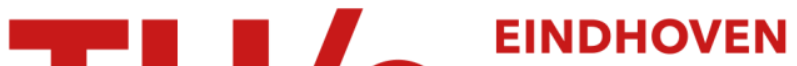 UNIVERSITY OF TECHNOLOGY
}

\section{Negative vibrational shift of nitrogen diluted in xenon at the fluid-solid transition}

\section{Citation for published version (APA):}

Kooi, M. E., Michels, J. P. J., \& Schouten, J. A. (1999). Negative vibrational shift of nitrogen diluted in xenon at the fluid-solid transition. Journal of Chemical Physics, 110(2-12), 3023-3025. https://doi.org/10.1063/1.477896

DOI:

10.1063/1.477896

Document status and date:

Published: 01/01/1999

\section{Document Version:}

Publisher's PDF, also known as Version of Record (includes final page, issue and volume numbers)

\section{Please check the document version of this publication:}

- A submitted manuscript is the version of the article upon submission and before peer-review. There can be important differences between the submitted version and the official published version of record. People interested in the research are advised to contact the author for the final version of the publication, or visit the $\mathrm{DOI}$ to the publisher's website.

- The final author version and the galley proof are versions of the publication after peer review.

- The final published version features the final layout of the paper including the volume, issue and page numbers.

Link to publication

\section{General rights}

Copyright and moral rights for the publications made accessible in the public portal are retained by the authors and/or other copyright owners and it is a condition of accessing publications that users recognise and abide by the legal requirements associated with these rights.

- Users may download and print one copy of any publication from the public portal for the purpose of private study or research.

- You may not further distribute the material or use it for any profit-making activity or commercial gain

- You may freely distribute the URL identifying the publication in the public portal.

If the publication is distributed under the terms of Article 25fa of the Dutch Copyright Act, indicated by the "Taverne" license above, please follow below link for the End User Agreement:

www.tue.nl/taverne

Take down policy

If you believe that this document breaches copyright please contact us at:

openaccess@tue.nl

providing details and we will investigate your claim. 


\title{
Negative vibrational shift of nitrogen diluted in xenon at the fluid-solid transition
}

\author{
M. E. Kooi, ${ }^{\text {a) }}$ J. P. J. Michels, and J. A. Schouten \\ Van der Waals-Zeeman Institute, University of Amsterdam, Valckenierstraat 65, 1018 XE Amsterdam, \\ The Netherlands
}

(Received 20 October 1998; accepted 4 November 1998)

\begin{abstract}
It is known from experimental evidence that the Raman shift of nitrogen and nitrogen in argon, measured as a function of the pressure at ambient temperature, reveals a positive jump at the transition from the liquid to the solid phase. Intuitively, this increase is sometimes attributed to the increase of density, but recently it has been shown that the change in order at the transition also plays a role. The present study deals with the behavior of nitrogen diluted in xenon. In this system, even a negative jump is found experimentally. Computer simulations on a model system for the $\mathrm{N}_{2}-$ Xe mixture make clear that in this case the effect of the change in order is opposite. (C) 1999 American Institute of Physics. [S0021-9606(99)01006-5]
\end{abstract}

\section{INTRODUCTION}

A positive jump of the Raman frequency of nitrogen has been found experimentally ${ }^{1,2}$ at solidification at ambient temperature in the pure substance as well as in a dilute mixture in argon. It has been remarked elsewhere ${ }^{3}$ that this increase is due to the increase of density. This seems in contrast with experimental and simulation results in the homogeneous system which reveal an almost constant frequency under isobaric conditions. $^{4}$

It is well known that the vibration frequency of nitrogen molecules, as for many other polyatomic molecules, is influenced by the interaction with surrounding particles. First, the neighboring molecules exert forces on the nitrogen atoms that change the bond length. Because the interatomic force is not harmonic, the change in bond length results in a shift of the frequency. Further, the interaction forces with the surrounding molecules will not be homogeneous, which causes a change in vibration frequency as well. It is interesting to survey this behavior in both phases near the fluid-solid transition. Recent computer simulations ${ }^{2}$ have shown that the interaction between the nitrogen molecules and their surroundings must be regarded in detail to understand the observed results. Simulations at equal density and temperature at both sides of the melting line (thus, one in a metastable phase) still reveal a higher frequency in the solid, for pure nitrogen and for nitrogen in argon, notwithstanding the lower pressure in the latter phase. The radial distribution in line with the molecular axis is essentially for the shift. Although the first peak of the mean, omnidirectional radial distribution function shifts to larger distances in the solid phase, this peak shifts to lower distances for the distribution in line with the molecular axis, both in the case for pure nitrogen as well as for the dilute mixture with argon. A corollary assumption may be that the positive jump in the shift will be less in dilute mixtures of nitrogen with host molecules which are larger in size and consequently crystallize on a larger grid

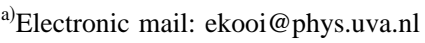

than nitrogen and argon. Even the occurrence of a negative jump may be possible.

In order to investigate this conjecture, the vibration frequency of nitrogen diluted in xenon at the fluid-solid transition has been determined by means of Raman spectroscopy. In addition, we performed dynamical computer simulations on a corresponding model system. The choice for xenon is evident: it crystallizes at the fluid-solid transition into the same (fcc) structure as argon, but with an $\sim 15 \%$ larger intermolecular distance.

\section{EXPERIMENT}

At ambient temperature the transition pressure for xenon is only about $0.4 \mathrm{GPa}$, which is relatively low in comparison to the transition pressure of $1.3 \mathrm{GPa}$ for argon. Also the density around the transition is much less in xenon. Since the measurements have to be performed at low concentrations of nitrogen, these circumstances would lead to relatively weak spectral lines, in particular in the fluid phase. Besides, it is preferable to perform the experiments at pressures which are at least of the same order, as the Raman shift turns out to be directly related to the pressure. Therefore the measurements have been performed at $408 \mathrm{~K}$. At this temperature the transition occurs at $\cong 0.85 \mathrm{GPa}$ and $\cong 28 \mathrm{kmol} / \mathrm{m}^{3}$.

High purity gases have been used to prepare a $\mathrm{N}_{2}-\mathrm{Xe}$ mixture with a nitrogen mole fraction of 0.075 . Employing the equations of state of $\mathrm{N}_{2}$ and Xe just below the fluid-solid transition, this leads to a volume fraction of approximately 0.05 . The mixture was kept in the gas compressor at 42 bar for several weeks to allow for proper mixing. The high pressure was achieved by using the diamond anvil cell (DAC) technique. The experimental procedure has been described in Ref. 6.

The appearance of a solid phase in the cell can be detected clearly by visual observations through a microscope. The fluid phase is completely transparent. When the pressure is raised above $0.83 \mathrm{GPa}$ a solid-fluid coexistence region is seen in which the amount of solid increases with pressure. In 


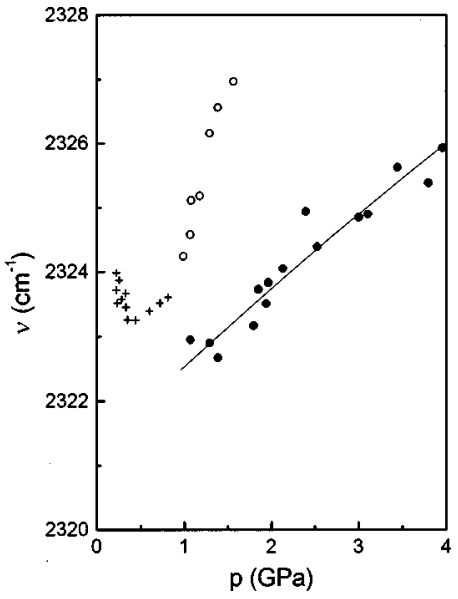

FIG. 1. Experimental results for the Raman shift of the $Q$ branch of nitrogen, diluted in xenon as a function of pressure at $408 \mathrm{~K}$; (crosses) homogeneous fluid phase, (solid circles) solid phase, (solid line) curve fit using Equation (1), (open circles) coexisting fluid phase.

the homogeneous fluid phase, only one single Raman peak has been observed $\left(\nu_{F}\right)$. This peak position as a function of pressure shows a minimum value of $2323.2 \mathrm{~cm}^{-1}$ at about $0.4 \mathrm{GPa}$ (Fig. 1). Just before the entrance point to the coexistence region at $p=0.81 \mathrm{GPa}$, this vibrational frequency is $2323.6 \mathrm{~cm}^{-1}$. Above the transition two vibrons are measured, and therefore the spectrum has been fitted by two Lorentzian curves. Since the Raman spectrum consists of two peaks above the transition, it is interpreted as one peak corresponding to $\mathrm{N}_{2}$ in the fluid phase, and the other peak corresponding to $\mathrm{N}_{2}$ in the solid xenon phase. The intensity of the high frequency peak $\nu_{F}$ compared with that of the low frequency peak $\nu_{S}$ decreases with increasing pressure, and therefore $\nu_{F}$ is attributed to the Raman mode of $\mathrm{N}_{2}$ in the fluid phase, and consequently, $\nu_{S}$ to the Raman mode of $\mathrm{N}_{2}$ in the solid phase. In Fig. 1 it is shown that the frequency $\nu_{F}$ above the transition connects to the frequency which was measured in the homogeneous fluid phase. The change in the slope of $\nu_{F}$ versus the pressure above the transition is due to a continuous change in the concentration of the fluid in the coexistence region to higher nitrogen contents, since the frequency is strongly composition dependent. Above $1.6 \mathrm{GPa}$ the high frequency peak is no longer measurable. Therefore, we can conclude that the usual solid-fluid coexistence region, which occurs in binary mixtures, extends in this case until about 1.6 GPa. At higher pressures the entire sample crystallizes. The Raman frequency $\nu_{S}$ has been measured up to $15 \mathrm{GPa}$, and has been fitted with the following equation:

$$
\nu_{S}=2321.27+1.28 p-0.025 p^{2},
$$

where $\nu_{S}$ is given in $\mathrm{cm}^{-1}, p$ is in GPa, and the standard deviation is $0.25 \mathrm{~cm}^{-1}$. Using Eq. (1) for extrapolation gives a negative frequency shift of $\sim 1 \mathrm{~cm}^{-1}$ at the solid-fluid transition as shown in Fig. 1.

\section{SIMULATIONS}

The molecular dynamics (MD) simulations have been performed on a system consisting of 255 xenon model particles and one nitrogen particle in a cubic box with periodic

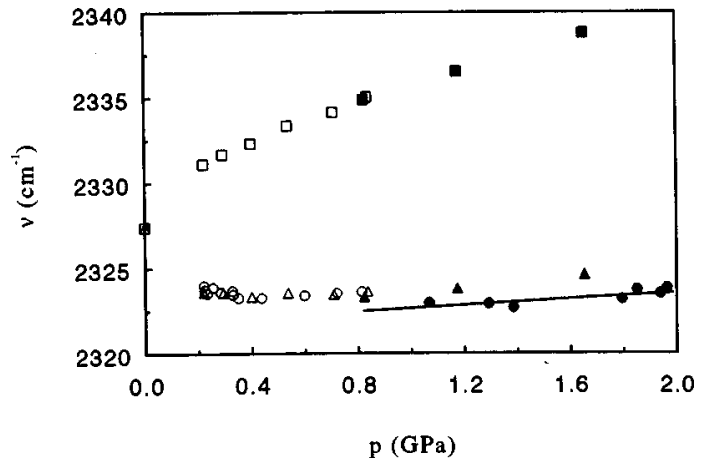

FIG. 2. Raman shift of nitrogen diluted in xenon at $408 \mathrm{~K}$ near the solid phase transition: (circles) experimental, (squares) MD results without DC, (triangles) MD results including the DC, (open symbols) fluid phase, (solid symbols) solid phase.

boundaries, allowing for a fcc structure in the solid phase. Note that the experiments have been performed at a volume fraction of 0.05 . A linear extrapolation to infinite dilution ${ }^{7}$ does not change the results essentially for the purpose of this investigation. For the intermolecular interactions between the xenon particles the exponential-6 potential model has been adopted. In conformity with previous simulations, ${ }^{2,8}$ the nitrogen molecule was defined as a site-site potential; each site (atom) interacted with the surrounding xenon particles with an exponential-6 potential as well. The parameters for the latter potential have been obtained using the LorentzBerthelot rule. The following parameter values have been used:

\begin{tabular}{lrcl} 
& $\epsilon / k_{B}(\mathrm{~K})$ & $r_{m}(\AA)$ & \multicolumn{1}{c}{$\alpha$} \\
\hline $\mathrm{Xe}-\mathrm{Xe}$ & 231.2 & 4.45 & 13 \\
$\mathrm{~N}_{\text {atom }}-\mathrm{Xe}$ & 95.4 & 4.09 & 13.75 \\
$\mathrm{~N}_{\text {atom }}-\mathrm{N}_{\text {atom }}$ & 39.4 & 3.73 & 14.55
\end{tabular}

intramolecular N-N distance: $1.094 \AA$.

The shift has been calculated from the forces acting along the axis of the nitrogen molecule in a way extensively described in previous publications. ${ }^{2,8}$ In short, the influence of the momentary forces and their derivative along the molecular axis on the vibrational frequency is calculated and added to the mean frequency $\nu_{0}$ of nonrotating, isolated molecules. From the value of $\nu_{0}$ obtained by Lavorel et al. ${ }^{9}$ at ambient temperature and the temperature dependence of the vibration-rotation coupling given by Brueck ${ }^{10}$ and Lavorel et $a .^{9}{ }^{9}$ this zero frequency was determined to $2327.41 \mathrm{~cm}^{-1}$. The results for the shift deviate from the experimental values. It is assumed that this difference is due to the change in the polarizability, and thus to the intermolecular energy at excitation. It is seen in previous work that one can correct for this energy change by the addition of a momentary energy term to the interaction potential, indicated as dispersion correction (DC). Results of the shift without the DC are given in Fig. 2 by squares. In order to lower these frequencies to the experimental results for the dilute mixture in the fluid phase, an energy term between each $\mathrm{N}_{\text {atom }}-\mathrm{Xe}$ interaction has been added. In contrast with simulations for pure nitrogen and mixtures with helium ${ }^{8}$ and with argon $^{2}$ one single term suffices for a good fit all over the fluid phase: 

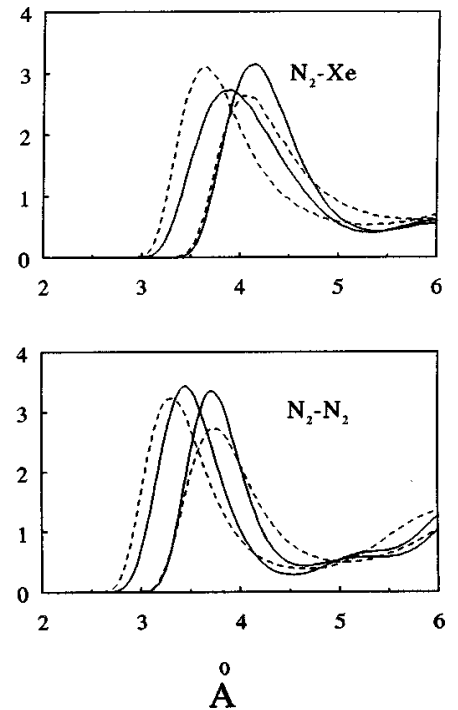

FIG. 3. Simulation results for the pair distribution relative to the center of mass of a nitrogen molecule in the fluid, and in a solid matrix: (upper) in xenon at $408 \mathrm{~K}$, (lower) in nitrogen (Ref. 2) at $296 \mathrm{~K}$; (solid line) solid phase; (dashed line) fluid phase; (left curves) perpendicular on the molar axis; (right curves) in line with the molecular axis.

$$
\delta \varphi_{i j}=b / r^{6} ; \quad b=2700 \mathrm{~K} \AA^{6} .
$$

For convenience, the same correction has also been used for the simulations in the solid phase, but this does not influence the main conclusions of this paper, because the DC is not involved in the dynamics and therefore has no effect on the structure in the fluid and solid phase. The results are displayed together with the experimental data in Fig. 2.

\section{DISCUSSION AND CONCLUSION}

It is seen that, going from the fluid to the solid phase, the experimental results for the shift reveal a negative jump of about $1 \mathrm{~cm}^{-1}$, in contrast with the positive jumps in pure nitrogen and argon (respectively, $\approx+1 \mathrm{~cm}^{-1}$ and $\approx+2$ $\mathrm{cm}^{-1}$ ). In order to show this more clearly, the fitted function (1) has been also drawn in Figs. 1 and 2. Note that this function is only slightly convex over the whole pressure range from 1 to $15 \mathrm{GPa}$; therefore the short extrapolation to $0.83 \mathrm{GPa}$ seems acceptable. The redshift in the fluid phase turns out to be several times more than in pure nitrogen and in dilute mixtures with argon and helium. ${ }^{2,8}$ From Fig. 2 a good correspondence is seen for the value of the shift in the solid phase, and the slope as a function of pressure, obtained experimentally and by simulations. In addition, the simulations do not reveal a positive jump of the frequency at the transition.

The results of the simulations in the fluid phase without DC are nearly the same as for pure nitrogen and the dilute mixtures mentioned above at room temperature in the same pressure range. Consequently, the DC is largest if the nitrogen is surrounded by xenon molecules, reflecting the high polarizability of xenon.

Two simulations have been performed at $p \approx 0.83 \mathrm{GPa}$ : one in the fluid and the other in the solid phase; evidently one of them is metastable. In both systems the radial distribution of xenon molecules around the nitrogen molecule has been determined in line with the molar axis of the nitrogen as well as in the perpendicular direction. It has been shown in a previous paper that in the case of pure nitrogen and nitrogen in argon, ${ }^{2}$ the first peak in line with the molar axis shifts to lower distances from the center of the nitrogen molecule at the transition to the solid phase, resulting in a larger force and consequently, a higher frequency. In Fig. 3 it is seen that this is not the case for nitrogen in xenon: a clear shift of this peak away from the nitrogen molecule is visible, in contrast with pure nitrogen for which the picture has been given as well in the same figure. This means that in the ordered matrix of solid Xe the force exerted on the nitrogen molecule in line with the atomic bond thus need not be higher than in the fluid phase or even may be lower. In that case the resulting vibration frequency will be less as well.

In summary: although the density increases at the fluidsolid transition, the vibrational frequency shows a negative jump in a dilute mixture of nitrogen in xenon. This is due to the change in order, but the effect is opposite that in nitrogen and nitrogen in argon.

${ }^{1}$ M. I. M. Scheerboom and J. A. Schouten, J. Chem. Phys. 105, 2553 (1996).

${ }^{2}$ J. P. J. Michels, M. E. Kooi, and J. A. Schouten, J. Chem. Phys. 108, 2695 (1998).

${ }^{3}$ Y. Guissani, D. Levesque, J. J. Weis, and D. W. Oxtoby, J. Chem. Phys. 77, 2153 (1982).

${ }^{4}$ M. I. M. Scheerboom, J. P. J. Michels, and J. A. Schouten, J. Chem. Phys. 104, 9388 (1996).

${ }^{5}$ A. Michels and C. Prins, Physica (Amsterdam) 28, 101 (1962).

${ }^{6}$ M. E. Kooi and J. A. Schouten, Phys. Rev. B 57, 10407 (1998).

${ }^{7}$ M. I. M. Scheerboom and J. A. Schouten, Phys. Rev. E 51, R2747 (1995).

${ }^{8}$ J. P. J. Michels, M. I. M. Scheerboom, and J. A. Schouten, J. Chem. Phys. 103, 8338 (1995); 105, 9748 (1996).

${ }^{9}$ B. Lavorel, R. Chaux, R. Saint-Loup, and H. Berger, Opt. Commun. 62, 25 (1987).

${ }^{10}$ S. R. J. Brueck, Chem. Phys. Lett. 50, 516 (1977). 